\title{
Discussion about the Development of Greenway with Region-Based Tourism
}

\author{
Jianrong Zhang, Zhenbin Zhao \\ School of Tourism and Environmental Studies \\ Shaanxi Normal University \\ Xi'an, China. \\ 4568118@qq.com
}

\author{
Jianrong Zhang \\ The Faculty of Management \\ Business College of Shanxi University \\ Taiyuan, China
}

\begin{abstract}
Region-based tourism” is an inevitable trend of the development of the tourism industry; it designates the strategic direction for the development of greenway which is an effective means to promote the realization of region-based tourism at the same time. But what kinds of models and strategies should implemented to greenway worth positive considering. Based on the analysis of the present situation of the constructions and researches of greenway in china, it is suggested that PPP (Public - Private - Partnership) mode and TGI (Tourism - Greenway - Integration) mode should be adopted. Combining with the concept of region-based tourism, we discussed the development strategies of greenway from the aspects of resource, product, function and market. We put forward innovatively that paying close attention to the needs of the users and the social education positions, giving full play to the value of the resources and deepening the connotation of the global tourism.
\end{abstract}

Keywords-Greenway; Region-based tourism; Development model; Strategies

\section{INTRODUCTION}

With the development of tourism, it has been to a new stage of national tourism and driving tour, the traditional scenic spots tourism model has been unable to meet the needs of modern tourists. It is called out that scenic spots attractions changed into the region-based tourism model for that the management and construction of closed scenic spots are fragmented and isolated from and even conflicted with social in the scenic model ${ }^{[1]}$.

Region-based tourism is a new regional development concept and model with coordinated economic and social development driving and promoting by tourism that where tourism as the dominant industry in a certain area, through the analysis of regional economic and social resources, especially enhancement of the all-round and systematic optimization and implementation of tourism resources and related industrieslecological environment/public servicelinstitutional mechanisms \policies and regulations $\backslash$ the quality of civilization to achieve regional resources integration, industrial merging development and social sharing. With the optimal allocation of economic and social development resources in accordance with the overall planning and construction of scenic standards, the construction of a comprehensive management system for tourism, tourism + function, the people to build and share the five distinctive characteristics of tourism.

People from all walks of life related to tourism have discussed region-based tourism from various aspects such as the awareness level \system level and the operational level while the strategies of its development on the schedule, but the specific operation level is a huge system and gradual process, there is still a lot to think deeply. Greenway as a kind of linear open space, which connecting corridors such as riverlvalley\ridge and other artificial corridors\abandoned railway lines\ditches and scenic roads ${ }^{[2]}$, it can effectively promote the network framework of region-based tourism and has been in the schedule of region-based tourism development. But it is still need to clear that how to play the function of greenway in region-based tourism and taking what kind of development pattern?

\section{GREENWAY}

Greenway is linear ecological open space connected natural, economic and social attractions, agglomeration and demonstration points together with ecological, leisure, sports, culture and traffic function, highlighting the green, wisdom, innovation, pragmatic and people-oriented concept, usually along the river shore, valleys, ridges, scenery roads, railways, canals and other natural and artificial corridor construction. There are landscape routes for tourists and cyclists, where may be main roads, nature reserves, scenic spots, historical sites and urban or rural residential areas ${ }^{[3]}$.

The modern greenway originated in the United States and Europe, from the focus on the landscape function of the avenue to green ecological network function of ecological corridor, the modern greenway has evolved over two centuries and become a global movement ${ }^{[4]}$. Especially since 1990s, greenway has been the research hotspot and frontier of conservation biology, landscape ecology, urban planning and landscape design ${ }^{[5]}$.

Europe and the United States and some Asian countries and regions started the construction of greenway earlier, the relevant theoretical research, planning and design and practice have developed to a more mature stage, and accumulated abundant achievements ${ }^{[5]}$. According to incomplete statistics, there are more than ten countries and regions in the construction and popularization of greenway, America, 
Canada and Brazil, Italy, Britain, France, Germany, Portugal, Bulgaria, Estonia, Japan, Singapore and Hongkong are mature in greenway development.

The shape and species of greenway are different ${ }^{[6]}$. It can be divided from different angles, and obtained different classification results according to the characteristics of greenway about space scale, natural ecology, regional landscape features and human resources ${ }^{[7]}$. But it is one of the main methods to classify according to function, which can be divided into ecological green road, recreational greenway and heritage type greenway ${ }^{[8]}$. The function of greenway is variety, it mainly involves ecology, leisure, education, economy, society and culture the function of greenway which can provide animal migration channel, can solve the problem of landscape fragmentation, the maintenance of ecological processes in nature, but may also have adverse ecological effects $^{[9]}$; The leisure function of greenway shows that it plays a role in improving the quality of life, bringing people opportunities to attach natural leisure, gaining health and comfort, and even community pride. Greenway is conducive to increase tourism revenues, drive the regional commercial prosperity and enhance the value of surrounding real estate, reduce diseases and medical expenses, also promote social and personal communication and has a good educational function ${ }^{[4-8]}$. The importance of social function of greenway has become more and more prominent.

\section{CONSTRUCTIONS AND RESEARCHES ABOUT GREENWAY}

\section{A. Researches of greenway in China}

The idea of the greenway in China can be traced back to the Zhou Dai of 1000 B. C., and it has been an important thought of the harmony between dynasties and nature. The target of greenway in the ancient China mainly embarked from the windbreak and prevented soil erosion and protected the natural environment, also built with political intentions to resist the foreign aggression, rarely involved the network function of modern greenway ${ }^{[11]}$. In the early stage,we mainly focused on the introduction of foreign theories and experience about greenway of function, significance, structure, type and scale of greenway ${ }^{[12]}$. Since 2000, affected by the trend of European greenway network construction, Chinese experts begin to pay attention to ecological protection\recreation\cultural heritage protection and other functions or characteristics of greenway network and planning methods based on landscape ecology ${ }^{[12]}$. From the perspective of urban green space system and ecological network, analyzing the ecological and recreational function of greenway in the city, which is mainly represented by Professor Liu-Binyi in the school of architecture and urban planning, Tongji University; analysis of natural ecological functions of greenways from the perspective of landscape ecology and cultural heritage protection functions from the perspective of the protection of historical and cultural features, the study is mainly represented by Professor Yu-Kongjian of the landscape planning and design center of Peking University; putting forward the concept of recreational belt around metropolis, which is mainly represented by Professor $\mathrm{Wu}-$ Bihu in the center of tourism research and planning, Peking University; analyzing the development of tourism in the regional greenway from the point of view of scenic spots, which is mainly represented by Professor Yu-qing in the Institute of landscape and tourism planning, Beijing Jiaotong University $^{[11]}$. At present, with gradual accumulation of the relevant experience of the greenway construction and development, the research focus also has changed from the early introduction of foreign experience to domestic experience, economic and social benefits and development evaluation, tourist satisfaction and so on ${ }^{[12]}$.

There has been a growing correlated analysis about regionbased tourism thoughts and greenway; In addition, it is more significant that the material space construction is turning to the humanism orientation, which pay more attention to the experience and needs of tourists, but the researches about ecological planning and design methods, relevant implementation policies, investment and financing system and management methods are relatively less ${ }^{[11]}$, moreover, the construction and development of greenway are still need further discussion under the guidance of region-based tourism.

\section{B. Constructions of greenway in China}

The construction of greenway started late in China ${ }^{[13]}$. In 1990s, the practice of greenway planning and construction is the main green space system planning of afforestation and greenway in various regions is basically built along the railway, highway, river and city road system. Emphasizing the construction of green belts on both sides of the linear space, greenway is limited to the level of forestry and related to industries landscaping, which as the most basic steps in the process of implementation of greenway ${ }^{[14]}$. Since 2000, the State Council issued the " Notice on further promoting about the construction of national greenway " pointed out that the "construction of greenway is an important part of China's territory virescence, the main task is afforestation and beautification along highway, railway, canals and dams. Following that, Zengcheng in Guangdong province first attempted greenway construction in 2008; then a number of provinces and cities to start greenway constructions, Ministry of Housing and Urban-Rural Construction issued greenway planning and design guidelines in 2016. At present, part of the urban areas in China began to carry out comprehensive Greenway Planning and construction, especially Guangdong where has the most and the largest scale. Guangdong took the lead in building the first greenway network learning from foreign experience, which marks an important step in the practice of greenway in china. After Guangdong, the distinctive "China greenway movement" set off across the country, except in the Pearl River Delta region of Guangdong Province, Beijing, Chengdu, Haikou, Jiaxing, Wenzhou, Wuxi, Nanjing, Jiangyin, Wuhan, Mianyang, Quanzhou, Ganzhou and other cities have also been carried out or intended to carry out special greenway planning and construction. At the same time, it is accompanied by the enthusiasm of scholars for the academic research of greenway.

\section{DEVElopment STRATEgIES}

We have accumulated a lot of achievements with development and research of greenway in China ${ }^{[11]}$, but it is 
still of great value to consider the function and effect of greenway from the perspective of region-based tourism.

\section{A. Innovate application of region resources to give full play to the value of resources}

The concept of region-based tourism extends the connotation of tourism resources what are no longer simply specific tourist attractions, resources all within the region can become integral part of tourism resources, but the using for tourism will inevitably be restricted by the tour routes and accessibility. Therefore, it is the way to make use and dig out the value of resources and bring about the organic integration of regional resources and industrial merging by relying on the greenway traffic to form a series network system, achieving urban spatial connection and resource combination, and bring some ancient folk houselbusiness centerltheme parklmemorial hallıold factories or roads into the greenway network system.

\section{B. Promote the innovation of leisure products, and to deepen the connotation of region-based tourism}

To expand and deepen the connotation of region-based tourism and pave innovation path for leisure products combined from public's active participation and application of high technology, meanwhile, with the concept of landscape, culture and experience of region-based tourism. As in riding leisure, strengthen cooperation with public or sharing bike organization, take slow ride travel as the core location, enrich riding facilities and services, bicycles for adults or children, small tricycle for the elders and other forms of bicycle. It can be also open up the specialized knowledge about ride, such as structure and civilization, benefits of riding and the matters needing attention, maintaining the necessary communication with relevant organizations or clubs.

\section{Extend tourism function of greenway to take as an important position for social education}

On the one hand, it can connected university library, exhibition hall, historical and cultural relics and other places through the greenway, including the formation of education theme line; In addition, the greenway as ecological open space, can carry out cultural, natural, ecological, agriculture, environmental protection, aesthetics, science, photography, health and other forms of education. It will also enhance the overall tourism quality and level of social civilization by paying attention to spirit rendering of greenway and promoting the content of greenway through educational activities, which is also the ultimate goal to pursue regionbased tourism.

\section{Emphasize the building of the whole nation and actively pay attention to the needs of users}

Pay close attention to the feedback of greenway users, especially carry out survey about users regularly to understand the problems to optimize the construction and management services of greenway. Really understand the safety, identity interpretation, infrastructure and supporting services, post, rest area, viewing platform, public toilets and sharing bicycle rental points and other diversified demands. In addition to the relevant experts, but also the builders, consider the opinions and suggestions of local residents and tourists into development process of greenway, keeping continuous optimization and improvement and assembling the power of the crowd to find a new attempt to promote the greenway in the aspects of space, elements, process, structure, system of region-based tourism.

\section{DEVElopment Models}

Development of greenway is closely related to the role of government, land resources and industrial distribution. At present ${ }^{[3]}$, it still has such problems as weak investment construction, single function, lack of legal guarantee, poor public participation, insufficient product and consumption, weak guarantee and weak service in China. It is the fundamental way to solve these trivial symptoms to explore the development model with guiding significance.

\section{A. PPP (Public - Private - Partnership) model}

It is a model to take advantage of the public-private partnership between the government and the organization (or private enterprises) to cooperate in the construction of green infrastructure projects and the development latter ${ }^{[15]}$. We can not consider the investment operation and management of the greenway with social service properties obviously, therefore, taking PPP model that private enterprises or organizations dominate greenway construction and operation and government participate in the whole development process is a combination of flexibility and stability, as well as elastic operation and government supervision. Constructing community relations between the government and social subject for benefit sharing, risk sharing and full cooperation, the government's financial burden and social investment risk are all reduced. Promoting the diversifications of investment construction and operation management is also an important part of the region-based tourism development. However, it is necessary to further clarify the responsibilities of government departments and improve the legal system.

\section{B. TGI(Tourism-Greenway-Integration)model}

The function of the existing greenway in China is still to meet the residents' daily leisure and recreation, the tourism function of greenway has not been well developed ${ }^{[12]}$. Thus it is an important model for the development of greenway to regard greenway as a necessary region-based tourism network system, to realize the integrated development of tourism and greenway, and enhance the attraction and tourism function of greenway which is not only a place of leisure for local residents, but also tour products and image windows.

Greenway had become important tourism resources through unique attracted form and activity contents ${ }^{[16]}$. It will be in ecological harmony with function extension, achieving market efficiency by the tourism channel and sustainable development. Taking tourism as a breakthrough, promoting the whole industry chain of region-based tourism and sports investment, not only to achieve regional ecological protection and promote the regional industrial activities, both the tourism function and the beauty of connotation, ultimately, implement the region-based tourism. It is not just to achieve 
tour\transportation\living \food \shoppinglentertainment in greenway, but also to achieve the cultural\deep\slow\ramblinglexquisitelat best, and ultimately promote the transformation from scenic tourism to regionbased tourism.

\section{CONCLUSION}

With the gradual development of greenway and the accumulation of relevant experience, it is very necessary to carry out region-based tourism relying on greenway. The greenway what we are talking about is the inevitable product of a certain stage with social and economic development, it is not only the repair and maintenance of natural ecological environment, but also a kind of low carbon green public open space in order to meet the people's recreational demands ${ }^{[17]}$.

To carry out construction of greenway from the angle of ecological protection and social demand angle, pay attention to the width, accessibility, road and ancillary services, humanistic concern and so on. It needs strive for innovation in resources, products, functions, and requirements based on the specific form and content of greenway construction. To break the regional boundaries in the form of greenway which can provide ways and means for the development of the regionbased tourism; Secondly, it will have positive guides for further hierarchical design of greenway and strategic goals according to the region-based tourism thought. And thus we can promote the development, construction and operation management of greenway, and gradually realize the regionbased tourism with the choice of PPP model and TGI model, relying on public-private partnerships to integrate tourism development.

\section{REFERENCES}

[1] Cui Y. Directional Choice of Jilin Region-based Tourism Development[J]. China Opening Journal, 2016.(In Chinese)

[2] Deenihan G, Caulfield B, O'Dwyer D. Measuring the success of the Great Western Greenway in Ireland[J].Tourism Management Perspectives, 2013, (7):73-82.
[3] Miller F P, Vandome A F, Mcbrewster J, et al. Greenway (Landscape)[M]. Alphascript Publishing, 2010.

[4] Olszewska A A, Marques P F. Contemplative Greenway Design for the Health and Well-Being of City Inhabitants[C]// Fabos Conference on Landscape and Greenway Planning. 2016.

[5] Li C H, Zhu X D. Development of greenway construction in foreign countries and its revelation for China's urbanization.[J]. World Forestry Research, 2007, 20(3):34-39.(In Chinese)

[6] Lusk A C .Guidelines for greenways:determining the distance to, features of , and human needs met by destinations on multi-use corridors [D].Doctoral Dissertation of University of Mi chigan , 2002.

[7] Gobster P H, Westphal L M. The human dimensions of urban greenways: Planning for recreation and related experiences[J].Landscape and Urban Planning, 2004, 68 (2-3):147-165.

[8] Furuseth O J, Altman R E. Who's on the greenway: socioeconomic, demographic, and locational characteristics of greenway users.[J]. Environmental Management, 1991, 15(3):329-336.

[9] Imam K Z E A. Role of urban greenway systems in planning residential communities: a case study from Egypt[J]. Landscape \& Urban Planning, 2006, 76(1):192-209.

[10] Munder L, Coenders G. Greenways: A sustainable leisure experience concept for both communities and tourists[J].Journal of Sustainable Tourism, 2010, 18(5):657-674.

[11] Ma X, Qi T, Wu M. The Comparative Research of Urban Greenway Both at Home and Abroad[J]. Journal of Capital Normal University, 2014.(In Chinese)

[12] Jiao Jianchun. Preliminary discussion on the operations management and tourism development of China's greenways [J]. Modern Urban Research, 2012,(3):19-23.(In Chinese)

[13] Liu K, Siu K W M, Gong X Y, et al. Where do networks really work? The effects of the Shenzhen greenway network on supporting physical activities[J]. Landscape \& Urban Planning, 2016, 152:49-58.(In Chinese)

[14] Lin Li. Studying the Greenways Landscape Construction of Country Ecotourism in the Xiaolou Town[D]. Guangzhou: South China University of Technology, 2011:15-17.(In Chinese)

[15] Peric' M. Criteria for setting up the public-private partnership in Croatian tourism and selection of optimal public-private partnership model.[J]. Business Excellence, 2009, 3(2):111-125.

[16] Fabos Julius. Greenway Planning in the United States: its origins and recent case studies[J]. Landscape and Urban planning,2004(68):321-342.

[17] Liu Qi. The Application Research of the Greenway in Urban Tourism Development: Taking Greenway Tourism Master lanning of Xunshan, Rongcheng City as an Example [D]. Tai'an: Shandong Agricultural University, 2013.(In Chinese) 